\title{
DESCARTE DE EMBALAGENS DE AGROTÓXICOS
}

\author{
JOSÉ ADALBERTO DE ALENCAR * \\ MIRTES FREITAS LIMA **

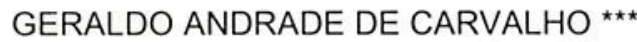 \\ CHARLES MARTINS DE OLIVEIRA ***
}

\begin{abstract}
Efetuou-se revisão de literatura sobre o descarte de embalagens e de resíduos de agrotóxicos. Foram discutidos os aspectos legais, o impacto ambiental causado pelo uso intensivo de agrotóxicos, os tipos de embalagens e os métodos (biológicos, físicos e quimicos) utilizados para o seu descarte, além daqueles para recuperação/reciclagem. Concluiu-se que é necessário o estabelecimento de açăo conjunta entre instituições governamentais, empresas produtoras e usuários destes produtos visando a conscientização quanto ao uso adequado e seguro de agrotóxicos, além da destinação final correta de embalagens vazias e de resíduos.
\end{abstract}

O Brasil encontra-se entre os principais consumidores de agrotóxicos em nivel mundial (40). Em 1991, apenas no Paraná, o consumo de agrotóxicos foi de 24.000 toneladas, estimando-se que cerca de 12 milhões de embalagens contaminadas são, anualmente geradas, segundo a Secretaria de Agricultura e Abastecimento daquele Estado (40).

Um dos principais problemas da indústria de agrotóxicos é o descarte de embalagens (37). Na década de 70 , mais de um milhão de embalagens foram descartadas, nas quais a permanência do produto concentrado foi de $0,3 \%$, resultando no despejo de cerca de 500 toneladas de agrotóxicos por ano no meio ambiente (22). Residuos de formulações

- Engenheiro Agrônomo, M.Sc. em Entomologia, Empresa Brasileira de Pesquisa Agropecuária (EMBRAPA-Semi-Árido), Petrolina - PE.

* Engenheira Agrônoma, M.Sc. em Fitopatologia, EMBRAPA-Semi-Árido, Petrolina - PE.

... Engenheiro Agrônomo, M.Sc. em Entomologia, Bolsista/CNPq, ESALQ, Piracicaba - SP 
viscosas, como suspensões e emulsões concentradas, e as formulações oleosas podem ficar retidas em maiores quantidades nas embalagens.

No Brasil, a legislação em vigor estabelece que é de responsabilidade do fabricante o fornecimento de informações técnicas necessárias ao destino final das embalagens de agrotóxicos (40). O Instituto Brasileiro do Meio-Ambiente e dos Recursos Renováveis (IBAMA) vem orientando os agricultores quanto à lavagem, inutilização, escolha de locais para enterro das embalagens e quanto à construção de fossos sanitários para o descarte do lixo tóxico (40).

Embora muito recomendadas, as medidas para o descarte seguro nem sempre são seguidas. O que, geralmente, observa-se em campo é o abandono de embalagens nos locais de abastecimento dos pulverizadores, próximo a mananciais de água e a sua reutilização ou venda para outros fins (31), como o acondicionamento de alimentos (40). A incineração em baixas temperaturas, processo que volatiliza os residuos quimicos remanescentes nas embalagens, é uma técnica bastante comum, entretanto, não há critérios com relação à escolha do local da queima (14). O processo de queima e o descarte de embalagens não lavadas constituem-se em fontes poluidoras em potencial do meio ambiente e podem causar a contaminação de mananciais hídricos e intoxicação de pessoas e de animais (31).

A utilização racional de agrotóxicos, o descarte correto de embalagens e de resíduos, leis de proteção ambiental, restringindo ou proibindo o uso dos agrotóxicos mais poluentes e o uso obrigatório, pelo operador, dos equipamentos de segurança na hora da aplicação, são medidas que podem reduzir os problemas causados por estes produtos ao meio ambiente $(7,20,23,34,35)$.

A presente revisão de literatura teve como objetivo levantar informações sobre o descarte de embalagens e de residuos de agrotóxicos.

\section{O PROBLEMA DO IMPACTO AMBIENTAL}

São considerados residuos de agrotóxicos, traços remanescentes de produtos aplicados na lavoura, embalagens não utilizadas, restos de calda, água de lavagem de embalagens e de equipamentos e embalagens vazias. Os residuos estão relacionados com a natureza do produto ou com o tipo de formulação (persistência), freqüência de aplicação, dosagem (acúmulo) e interação com o ambiente, através da degradação ou recombinação. A maioria dos agrotóxicos é poluidora ou contaminante em potencial do ambiente, e, conseqüentemente, as fases de produção, transporte, manuseio e armazenamento destes produtos devem ser muito bem planejadas $(16,25,26,35)$. 
Por vários anos, quando não havia preocupação com a contaminação ambiental, o solo foi considerado local seguro para o depósito de residuos e de embalagens vazias de agrotóxicos $(7,27,45)$. Nos Estados Unidos, esta prática causou contaminação de 11.000 poços, metade dos quais apresentaram residuos em niveis elevados de pelo menos um produto, e a outra metade residuos de 73 produtos em níveis considerados não prejudiciais ao ambiente (7).

Os agrotóxicos, quando em contato com o solo ou com a água podem originar três tipos de reação: degradação completa sem a formação de metabólitos; degradação incompleta com o acúmulo de metabólitos não degradáveis; e, pequenas alterações levando ao acúmulo e à alta persistência dos produtos em função de aplicações sucessivas (43). A estimativa do tempo requerido para a perda de 75 a $100 \%$ da atividade dos agrotóxicos no solo, na agricultura convencional, pode variar de uma semana a sessenta meses para inseticidas, sendo de uma semana a três meses para os organofosforados e de vinte e quatro a sessenta meses para os clorados (28). Para os herbicidas, este tempo pode variar de um a seis meses para aqueles derivados de fenoxi, toluidinas e nitrilas e de um a dezoito meses para os herbicidas derivados de uréias, triazinas e picloram. No caso dos inseticidas organoclorados estima-se que, para a eliminação de $50 \%$ dos seus resíduos do solo sejam necessários de quatro a trinta meses, e para a eliminação de $95 \%$ de trinta e seis a noventa e seis meses (24).

Os agrotóxicos entram em contato com os lençóis freáticos através da água de percolação, que carrega o produto por lixiviação ou, ainda, quando os produtos atingem os canais ou poços que se ligam ao aqüifero. Isto ocorre, devido à utilização de agrotóxicos em áreas próximas aos poços, durante o bombeamento de água para o enchimento do tanque do pulverizador, na injeção de agrotóxicos em sistemas de irrigação e, também, no descarte de restos de calda e de água da lavagem do equipamento de pulverização (36). Os fatores que influenciam na contaminação dos lençóis freáticos são: propriedades dos agrotóxicos (solubilidade em água, volatibilidade, adsorsão ao solo e decomposição do produto no solo), características do solo (textura, conteúdo de matéria orgânica, umidade, $\mathrm{pH}$, temperatura e presença de microorganismos), práticas agrícolas (dosagem, tipo de defensivo utilizado, método de aplicação, freqüência e espaço de tempo entre irrigação e aplicação) e as condições geográficas da área (declividade e proximidade dos canais de escoamento, lagos e rios) (36).

Em 1980, o Conselho da Comunidade Européia (CCE), preocupado em controlar a contaminação de água por agrotóxicos, fixou a concentração máxima de resíduos na água potável em $0,1 \mathrm{ppb}$ (parte por bilhão) para quaisquer produtos, e em $0,5 \mathrm{ppb}$ a concentração total máxima de residuos (7). 


\section{3 \\ ASPECTO LEGISLATIVO AGROTÓXICOS \\ PARA O DESCARTE \\ DE}

A disposição final, correta e segura de embalagens vazias de agrotóxicos agrícolas tornou-se constante preocupação, principalmente, nos paises com agricultura altamente tecnificada, devido à utilização de altos niveis de insumos, como vem ocorrendo no Brasil. Este é um assunto complexo e as regulamentações vigentes em outros paises são bastante controversas, uma vez que alguns proibem, enquanto outros estimulam, a utilização de práticas como a queima, o enterro e a reciclagem de embalagens vazias.

No Brasil, o descarte de agrotóxicos e de suas embalagens é regulamentado pelo Decreto $n^{\circ} 98.816$, de 11 de janeiro de 1990, Capítulo IV, Seção III, Artigos 45 a 48. O Decreto proibe o reaproveitamento de embalagens de agrotóxicos e afins, a menos que devidamente autorizado pelo órgão federal registrante. A legislação ressalta ainda que, o descarte de embalagens e de residuos de agrotóxicos, deverá atender às recomendações técnicas apresentadas na bula do produto, observadas as exigências dos setores de saúde, agricultura e meio ambiente. No caso de agentes biológicos de controle, os residuos deverão ser incinerados. $O$ Decreto ressalta ainda que, os agrotóxicos e afins apreendidos por ação fiscalizadora terão destino final estabelecido, após a conclusão do processo administrativo, a critério da autoridade competente. E quando estes produtos forem formulados em desacordo com as especificações constantes no registro, terão o seu destino final determinado pela autoridade competente, sendo a execução de inteira responsabilidade da empresa produtora (8). Segundo as normas brasileiras, as embalagens vazias de agrotóxicos são classificadas no grupo I, como resíduo perigoso, - que exige a adoção de procedimentos especiais com relação à manipulação, transporte, armazenamento e disposição final (32).

A legislação especifica para descarte de embalagens deve estabelecer cronogramas para a implantação das diversas fases do processo de destinação, além do suporte técnico ao seu cumprimento (19). Deve estabelecer, também, a responsabilidade de cada um dos segmentos, compreendendo a produção de agrotóxicos e de suas embalagens, reciclagem de matérias-primas, canais de redistribuição (cooperativas agricolas, distribuidores, revendedores, etc.), divulgação (órgãos de extensão rural) e, especialmente, a conscientização dos usuários para a descontaminação das embalagens vazias e para a centralização do seu recolhimento.

Em países desenvolvidos, as indústrias produtoras orientam os usuários quanto ao descarte de produtos e de suas respectivas embalagens, sendo obrigatórias a lavagem e a inutilização de embalagens vazias. Nos Estados Unidos, o Governo divulga, anualmente, informações sobre o descarte de agrotóxicos e de suas embalagens. Em paises como 
Suécia e Holanda, embalagens não lavadas e com excesso de residuos são recolhidas como lixo químico, principalmente, aquelas provenientes de produtos das classes toxicológicas I e II.

Em junho de 1992, com o objetivo de diagnosticar a situação do descarte de embalagens de agrotóxicos em estados brasileiros e elaborar programa de recolhimento e destinação de embalagens, realizou-se no IBAMA, em Brasilia-DF, a primeira reunião sobre o assunto, visando a eliminação correta das embalagens descartadas no campo num prazo de até cinco anos (40).

\section{EMBALAGENS}

As embalagens para o acondicionamento de agrotóxicos têm recebido atenção especial das indústrias que vêm intensificando as pesquisas no sentido de melhorar as embalagens tradicionais e introduzir novas tecnologias, priorizando a segurança no manuseio em nivel de campo e disposição final pós-consumo (32).

Os principais tipos de embalagens para o acondicionamento de agrotóxicos são classificadas em rígidas, flexiveis e em embalagens para grandes volumes (1). As embalagens rigidas, utilizadas para liquidos, aerosóis, auto-propelentes, gases liquefeitos ou granulados, podem ser de vidro, metal (aço, alumínio, folha de flandres), plástico (polietileno de alta densidade - APEAD), polietileno tereftalato (PET), polietileno co-extrudado (COEX) ou fibrolatas (1). O vidro apresenta as seguintes vantagens: é transparente e não reativo, é impermeável a trocas gasosas e não adsorvente, não absorve umidade e não oxida, proporciona boa impressão em "silk-scream" e fácil fechamento, sendo resistente ao envelhecimento e reciclável, além de não produzir centelhas. Entretanto, estas embalagens são frágeis, pesadas, volumosas e de capacidade limitada. O Decreto de 11 de janeiro de 1990 impôs restrições à utilização do vidro, sendo recomendado apenas na ausência de embalagens mais apropriadas no mercado interno. Tal fato provocou aumento significativo no número de embalagens de plástico utilizadas, que passaram de $16,9 \%$ na década de 80 para $41,8 \%$ nos anos de $90 / 91$ (32). As embalagens metálicas são leves e de menor volume, moderadamente resistentes a impactos, impermeáveis a trocas gasosas; recicláveis e não absorvem umidade. Em contrapartida, são reativas, opacas, oxidáveis, apresentam revestimento interno frágil a impactos e com falhas na costura, o revestimento é adsorvente, o fechamento precário, produzem centelhas, estando sujeitas ao envelhecimento, a perfurações e a vazamentos. As embalagens de plástico são leves, de menor volume, não oxidáveis; não produzem centelhas e são resistentes a impactos. Entretanto, são opacas, com exceção do PET, reativas a certas formulações, adsorventes, absorvem 
umidade, são muito atrativas, permeáveis a trocas gasosas (com exceção do $(O E X)$ e de reciclagem problemática (1). As embalagens flexiveis podem ser de papelão, cartolina, papel multifolhado, plástico ou mistas (papel/plástico/metal) e são utilizadas para formulações em pó ou granulados. Estas embalagens podem rasgar ou furar com facilidade quando manuseadas incorretamente, além disso, depois de abertas são dificeis de fechar (36). As embalagens especiais podem ser retornáveis (Farm-pack, Trock-tank, U-turn, Compack), ou utilizadas como depósito fixo para reabastecimento (Bulk, capacidade de 5.000 - 10.000 litros) ou ainda serem hidrossolúveis (sacos hidrossolúveis) (11). Os dois primeiros tipos são utilizados para a transferência e armazenamento de grandes quantidades de agrotóxicos e não são descartáveis, o que reduz os problemas de impacto ambiental durante as operações de manuseio, transporte e armazenamento dos produtos $(11,23)$. As embalagens retornáveis são equipadas com sistema de transferência semi-fechado (bomba de transferência e medidor de vazão), o que reduz em até $90 \%$ a exposição do operador ao produto (14). As embalagens para grandes volumes, tipo Farm-pack e sistema Bulk, são equipadas com bomba e fluxômetro para a dosagem exata do produto diretamente no tanque pulverizador. Após a utilização do produto, a embalagem retorna ao fabricante para lavagem e reutilização. Os acidentes com estes tipos de embalagens são raros, entretanto, quando ocorrem, grandes quantidades de agrotóxicos vazam, podendo contaminar o ambiente (25). O saco hidrossolúvel, embalagem de um tipo especial de plástico hidrossolúvel, vem com dosagem determinada a ser depositada diretamente dentro do recipiente. Em contato com a água, a embalagem dissolve-se completamente em 1 ou 2 minutos. Deste modo, a exposição do operador ao produto é, praticamente, nula $(14 ; 44)$. O saco hidrossolúvel apresenta dispositivo externo de proteção que visa evitar problemas durante o transporte ou estocagem dos produtos (11).

A preferência dos agricultores é por embalagens tipo bombona de plástico $(79 \%)$, seguida por vidro $(11 \%)$, lata $(7 \%)$ e papel $(3 \%)(14)$.

Para a redução dos resíduos nas embalagens, permitindo lavagem efetiva e esvaziamento sem risco de contaminação do operador, ficou estabelecido que a embalagem padrão deve apresentar bocal largo para a saida do produto e entrada de ar sem a formação de bolhas (tipo funil), cantos arredondados para o completo escoamento do produto e alça bloqueada para evitar o acúmulo de residuos no local e facilitar a lavagem $(14,44)$. A embalagem ideal deve ser resistente, não reativa, impermeável a trocas gasosas/umidade, não adsorvente, transparente, incombustivel, leve, durável, facilmente litografável, cônica, com abertura ampla, ser totalmente esgotável, apresentar fecho inviolável, ser facilmente reciclável e de custo compativel.

Segundo a ANDEF (2) a distribuição das embalagens de agrotóxicos comercializadas no Brasil, nos anos de 1991/92, de acordo 
com o material de confecção e o tipo de embalagem foi: plástico (garrafas, sacos, bombonas e botijas) $56,05 \%$; vidro (frascos de $1 / 8$ a 1 litro) $16,66 \%$; embalagens metálicas (tambores, baldes, latas e aerosóis) 16,27\%; papelão (caixas coletivas: 2 a 50 unidades) $6,65 \%$; cartuchos de cartolina (cartuchos de 0,5 a 2,0 kg) 4,70\%; papel multifolhado (sacos de 1 a $30 \mathrm{~kg}$ ) $4,33 \%$ e fibrolatas (unidades de 5 a $25 \mathrm{~kg}$ ) 0,34\%. Em 1991/92 foram comercializadas cerca de 56 milhões de embalagens de agrotóxicos, o que corresponde a, aproximadamente, 13 mil toneladas (32).

\subsection{DESTINO DAS EMBALAGENS}

Segundo a ANDEF (2) 56 milhões de embalagens de agrotóxicos, sendo $56,24 \%$ de material plástico, $11,64 \%$ de vidro, $16,36 \%$ de metal e o restante em papel e fibrolatas, são colocadas no mercado, anualmente. Pesquisas realizadas pela EPAGRI (32) revelam que as embalagens vazias de agrotóxicos, no Estado de Santa Catarina, tiveram o seguinte destino: $38,5 \%$ foram abandonadas na lavoura e 9,5\% reutilizadas; $9,0 \%$ foram jogadas nos rios e $9,0 \%$ em fossos sanitários; $30,0 \%$ foram enterradas ou queimadas e $4,0 \%$ sofreram outros métodos de descarte. Tal situação pode ser bastante semelhante ao que ocorre com o descarte de embalagens de agrotóxicos em outros estados brasileiros.

Existem diferentes métodos para o descarte, segundo cada tipo de embalagem. A aplicação destes métodos está diretamente relacionada com às condições do agricultor e da região em que reside. Alguns destes métodos são destinados para fontes de descarga de fábricas de produção ou para formulações em pequena escala, como o enterro ou a deposição em fosso sanitário. Desta forma, torna-se dificil a padronização de método único, sendo comum a adoção de vários deles. A operacionalização dos métodos de descarte disponiveis é bastante complexa, exigindo a participação de todos os segmentos da sociedade.

$O$ destino final das embalagens vazias compreende as fases de descontaminação parcial no campo, o armazenamento primário na propriedade rural e intermediário no municipio ou na região (em instalações das prefeituras ou das cooperativas), separação de embalagens laváveis (metálicas, de plástico e de vidro) e não laváveis (sacos de papel multifolhado e de plástico, cartuchos de cartolina e papelão de caixas coletivas), redução de seu volume (moedores para vidro e plástico; prensas compactadoras para metal e enfardadeiras para sacos de plástico, sacos de papel multifolhado, papelão e cartolina), identificação de receptores/recicladores, reciclagem seletiva ou não, incineração com ou sem aproveitamento de energia ou ainda depósito em fosso sanitário (2, 19). 
Os processos de descarte de embalagens podem ser classificados em biológicos, quimicos e físicos.

\subsubsection{Métodos biológicos}

A degradação microbiana, a adsorção e a votilização, entre os métodos biológicos, são os fatores que mais influenciam no comportamento dos agrotóxicos no solo. A persistência de um produto químico no solo, ativação e desativação, está diretamente associada com a dinâmica populacional de microrganismos degradadores e sua atuação sobre estes produtos (38). Outros fatores como hidrólise, fotólise e outras reações químicas também atuam no processo.

A degradação é um processo que inclui transformações que podem originar produtos mais tóxicos do que o composto inicial (38). Sob condições de campo, além da degradação microbiana, da adsorção, da lixiviação, da volatilização e da absorção de produtos pelas plantas, há processos que também podem atuar na redução e no acúmulo de resíduos (24). Os principais fatores que influenciam a degradação de agrotóxicos por microrganismos no solo são: concentração ou freqüência de aplicação do produto, formulação, tipo de solo, adsorção, disponibilidade do composto, concentração de microrganismos degradadores, umidade, temperatura, $\mathrm{pH}$, teor de oxigênio e teor de matéria orgânica $(41,43)$. A utilização de culturas de microrganismos na degradação de produtos quimicos pode ser alternativa viável para casos de derramamento acidental de agrotóxicos (37).

Os métodos biológicos consistem na incorporação de residuos ao solo, no enterro de embalagens ou na utilização de aterros e sistemas de lodo ativado (45). A incorporação de residuos ao solo pode ser feita através de pulverizações dos produtos diretamente em solo cultivado ou com a utilização de sistemas de irrigação; através de compostagem; e, ou enterro em fossos sanitários ou em fossos secos (17).

O fosso sanitário deve ser feito em local isolado, distante de instalações, casas, fontes de água, do trânsito de pessoas e/ou animais e, sem possibilidades de futuro reaproveitamento agricola. A área de solo profundo e impermeável deve ser cercada e sinalizada com placa de advertência e não estar sujeita a inundações ou ao acúmulo de água (30). Deve-se dar preferência à construção de vários fossos pequenos em vez de um único grande. O fosso, compactado ou revestido de concreto ou lona de plástico para evitar a contaminação de lençóis freáticos, deve estar situado a $2,5 \mathrm{~m}$ de profundidade, no mínimo. No fundo são colocadas camadas de $30 \mathrm{~cm}$ de pedra britada, areia, calcário e carvão (13). Antes de ser utilizado, e a cada $15 \mathrm{~cm}$ de material descartado, deve-se intercalar camadas de cal virgem e calcário para a neutralização dos produtos e, após o seu enchimento é necessário cobri-lo com camada de cerca de 
$50 \mathrm{~cm}$ de solo bem compactado. $\mathrm{O}$ fosso com 1 a $2 \mathrm{~m}$ de profundidade deve ser cercado por valeta com escoadouro para impedir problemas com enxurradas.

A Secretaria do Meio Ambiente (SEMA) (42) não recomenda que se enterre embalagens vazias, porque esta prática pode inviabilizar áreas agricolas, contaminar lençóis freáticos, além de gerar lixo não degradável, como no caso das embalagens de plástico e de vidro. Entretanto, a SEMA e outros órgãos responsáveis não recomendam práticas mais racionais para o descarte de embalagens, e, portanto, fossos e aterros sanitários, por serem economicamente mais viáveis, são os métodos mais utilizados, principalmente, por pequenos agricultores, não apenas no Brasil, mas também, em outros países (32). Enterrar embalagens, após a sua destruição, é, atualmente, a única recomendação oficial de descarte (15).

A prática da compostagem consiste na incorporação de resíduos de agrotóxicos ao solo, juntamente, com restos de cultura, esterco e outras matérias orgânicas. Enquanto alguns agrotóxicos aplicados em altas concentrações esterilizam efetivamente o solo, outros induzem o metabolismo microbiano (45). A formulação do produto é extremamente importante na determinação do seu impacto e persistência. A umidade e a temperatura do solo também influenciam na degradação do composto.

\subsubsection{Métodos químicos}

A degradação de agrotóxicos através de métodos químicos ocorre pela detoxicificação do material tóxico ou remoção do produto quimico intacto dos efluentes industriais. Desta forma, o resíduo tratado pode ser manuseado com segurança e o produto recuperado, reciclado (45). Estudos com a utilização de métodos químicos determinaram a estabilidade de baixas concentrações de agrotóxicos no meio ambiente (37). Entretanto, não foi possivel extrapolar os resultados com relação à meia-vida e à cinética de degradação destes produtos quando estes ocorrem em altas concentrações no ambiente. Estes métodos são, geralmente, utilizados em indústrias de produção e formulação de agrotóxicos, nas quais o descarte de residuos é controlado através de sistemas (37). A desvantagem deste método está relacionada à destruição incompleta do produto, pois a reação química pode ocorrer em apenas certos grupos funcionais da molécula.

Os métodos quimicos mais comuns são hidrólise, oxidação e redução, adsorção e coagulação. 


\subsubsection{Métodos físicos}

Os principais métodos físicos utilizados são incineração e lavagem de embalagens vazias, antes da reciclagem ou descarte em fossos sanitários. Outros processos são a fotodegradação, a fixação e a adsorção.

A incineração é uma prática segura para o descarte de agrotóxicos e de suas embalagens, sendo o método mais recomendado para compostos orgânicos não metálicos. Os estudos sobre incineração têm se baseado, principalmente, no desenvolvimento de técnicas para o descarte de residuos especificos e no estabelecimento dos parâmetros necessários que assegurem combustão completa (37). Os fatores que afetam a taxa de combustão são temperatura, variando de 800 a $1.600{ }^{\circ} \mathrm{C}$, o tipo de material a ser incinerado, o tipo de incinerador e o tempo de exposição, geralmente, 2 ou 3 segundos na temperatura de incineração (27). A relação ar-combustivel e a concentração do produto devem ser consideradas $(45 ; 37)$, sendo mais adequadas, aquelas com teores de oxigênio inferiores a $7 \%$. Em concentrações superiores a $7 \%$, a combustão do produto não ocorre ou ocorre lentamente. A temperatura de $1000{ }^{\circ} \mathrm{C}$ ocorreu a combustão de vinte formulações de produtos comerciais, com eficiência de até 99\% (29), entretanto, a maioria dos agrotóxicos requer temperaturas inferiores a $1000{ }^{\circ} \mathrm{C}$ para sua destruição (22). Embalagens de polivinil, polietileno e teflon são destruidas a $900{ }^{\circ} \mathrm{C}$ (29). Os incineradores mais comuns são os fornos rotativos $\left(800-1000^{\circ} \mathrm{C}\right)$, para combustão de residuos sólidos e liquidos, e os incineradores de injeção liquida para os residuos liquidos. Estes últimos funcionam com temperaturas de 800 a $1600{ }^{\circ} \mathrm{C}$ e, nestes equipamentos, os resíduos são injetados sobre pressão (37).

Devido aos niveis de composição, às diferentes substâncias quimicas e ao estado físico das formulações dos agrotóxicos, os residuos resultantes da incineração destes produtos, quando gases tóxicos e contendo metais pesados e óxidos, podem contaminar o ar (22). Os agrotóxicos orgânicos e os inorgânicos, que apresentam metais em sua composição, devem ser submetidos aos tratamentos físicos e/ou quimicos para recuperação dos metais, antes de serem incinerados ou enterrados (48). Eventualmente, as embalagens podem ser incineradas a céu aberto. Nos Estados Unidos, a Agência de Proteção Ambiental permite a incineração de embalagens quando fiscalizada e realizada durante o dia, em locais abertos e isolados. Devem ser observadas a direção do vento, a temperatura, as chuvas e a quantidade do produto a ser incinerada (23). Os sistemas de incineração são estáveis e seguros, permitindo a destruição de grandes quantidades de produtos em escala industrial (37). Entretanto, além dos elevados custos de instalação e de operação, este método tem como desvantagem a necessidade do tratamento prévio dos 
residuos para recuperação dos metais, antes da incineração, e a falta de informações sobre o que ocorre quando os produtos são incinerados.

Os residuos internos em embalagens de agrotóxicos vazias podem atingir, até cerca de $1,0 \%$ do seu conteúdo original. Por isto, a lavagem de embalagens antes do descarte é extremamente importante (33), o que pode evitar o desperdício de produtos e a redução da contaminação ambiental devido ao descarte de embalagens não lavadas (44). A triplice lavagem é a técnica mais eficiente para a remoção de residuos de embalagens vazias. Após o escoamento do produto no tanque do pulverizador, por até 30 segundos, adiciona-se água à embalagem, em até $25 \%$ do seu volume. Tampa-se a embalagem, agitando-a por 30 segundos e despejando a água de lavagem no pulverizador. Repete-se esta operação por mais duas vezes e inutiliza-se as embalagens lavadas, perfurando aquelas de plástico ou metal, quebrando as de vidro e armazenando-as em fosso sanitário. Para o sucesso da tríplice lavagem, as embalagens devem ser lavadas logo após o seu esvaziamento, pois quando secas, dificultam a remoção de resíduos. O volume de água a ser utilizado em cada lavagem não deve ser inferior a $10 \%$ do volume total da embalagem em uma mesma carga do pulverizador. É recomendado evitar respingos ao agitar e o uso do equipamento de proteção individual. A triplice lavagem de embalagens removeu até $99,99 \%$ dos residuos de Cloripirifós, Endosulfan, Dimetoato, Fenvalerato, Lambda-cialotrina, Metidition, Monocrotofós e Trifluralina $(4,5,6,9,10)$.

A triplice lavagem tem sido divulgada por várias associações em todo o mundo, como a Britsh Agrochemicals Association (3), a National Agricultural Chemicals Association (39) e a Associação Nacional de Defesa Vegetal (2).

Recomenda-se a adoção da lavagem de embalagens não como prática isolada, mas integrada nas práticas de preparo de calda, transporte e aplicação, devendo ser sempre realizada próximo ao tanque de pulverização. A implantação da triplice lavagem na propriedade exige colaboração entre indústrias e órgãos oficiais, através dos serviços de extensão rural, promovendo e estimulando a sua utilização (44).

\subsection{RECUPERAÇÃO/ RECICLAGEM DE EMBALAGENS}

A reciclagem de embalagens de agrotóxicos é uma prática que exige rigoroso controle de todas as fases do processo, além de consumir energia, gerar residuos e custo, relativamente, três vezes maiores do que outros métodos como a incineração em centrais elétricas ou fornos de cimento (44). No Brasil, a comercialização de embalagens recicláveis pode ser feita pela empresa produtora, desde que autorizada pelo órgão federal registrante, segundo o Decreto ${ }^{\circ} 98.186$ de 11 de janeiro de 1990 (21). 
As embalagens de agrotóxicos nunca devem ser reutilizadas e o seu descarte deve sempre ser feito segundo as recomendações técnicas. As embalagens de vidro, plástico ou metal, de formulações liquidas devem passar pela tríplice lavagem, após o seu esvaziamento. No caso da incineração, as embalagens podem ser queimadas em local isolado, ao em hora de pouco ou nenhum vento. As embalagens vazias de plástico PVC ou de papel multifolhado podem ser enterradas em fosso sanitário ou queimadas, e as de metal e de vidro, após lavagem, podem ser comercializadas como sucata.

A reciclagem quimica, tecnologia desenvolvida recentemente pela indústria petroquímica, recupera matérias-primas para a produção de resinas a partir de residuos plásticos. Entretanto, este é um método ainda restrito a alguns tipos de resinas. Através da reciclagem mecânica, a indústria converte o residuo plástico novamente em grânulos. Este método é utilizado na Flórida, onde unidades móveis deslocam-se no campo transformando embalagens descontaminadas em grânulos que serão reutilizados na confecção de novas embalagens (18).

A Agência de Proteção Ambiental dos Estados Unidos regulamentou a lavagem de embalagens como parte dos processos de descarte e reciclagem, considerando que a triplice lavagem pode remover até $99,99 \%$ do ingrediente ativo de recipientes de plástico e de metais não resfriáveis. Segundo DALDIN (14) as embalagens, após o esgotamento, retêm quantidades variáveis de agotóxicos em seu interior, dependendo do seu tamanho, superficie interna e formulação do produto.

\section{5}

\section{DESTINO FINAL DE RESTOS DE AGROTÓXICOS}

É necessário ressaltar que não apenas as embalagens são fontes potenciais de contaminação do meio ambiente, mas também, restos de calda, água de limpeza de equipamentos, restos de agrotóxicos e agrotóxicos formulados fora das especificações ou que encontram-se fora do prazo de validade. Para evitar os problemas de sobras de misturas destes produtos deve-se procurar preparar apenas a quantidade de calda necessária a ser aplicada na área. Havendo sobras procura-se áreas nas quais o resto da mistura possa ser utilizado com o mesmo objetivo inicial (36). Residuos dentro e fora do tanque do pulverizador podem contaminar a aplicação seguinte e o aplicador. Portanto é importante procurar eliminar estes residuos através da lavagem do equipamento a ser feita em local adequado para evitar o escoamento para os cursos d'água ou lençóis subterrâneos $(46,47,12,36)$.

O destino de agrotóxicos vencidos ou produzidos fora das especificações é estabelecido pelos artigos 46, 47 e 48 do Decreto n 98816, de 11 de janeiro de 1990 (21), segundo o qual o descarte de residuos de agrotóxicos deve atender às recomendações técnicas. 


\title{
CONSIDERAÇÕES FINAIS
}

A tecnologia desenvolvida e disponivel, até o momento, para o setor agrícola não possibilitou o estabelecimento de um sistema de agricultura sustentável, de modo a atender à crescente demanda populacional sem causar desequilibrios ao meio ambiente. A consciência do perigo da poluição ambiental em decorrência da ampla aplicação de agrotóxicos tem sido crescente, o que tem demandado maior segurança e produtos seletivos.

A agricultura brasileira passou por transformações significativas nas últimas décadas. Entretanto, se por um lado houve ganhos significativos em produtividade, a utilização excessiva de insumos levou à formação de rejeitos, geralmente, associada a residuos de produtos fitossanitários, o que tem causado poluição do meio ambiente pela acumulação de residuos, particularmente de agrotóxicos. Este aumento ocorrido no consumo de agrotóxicos decorre, principalmente, da expansão das áreas cultivadas e, também, da sua intensa utilização em culturas de grande importância econômica.

Os agrotóxicos constituem-se em importante fator para aumentar a produção agrícola, reduzindo os problemas causados por pragas e doenças. Entretanto oferecem também, grande risco a saúde do homem, das plantas, dos animais e ao meio ambiente, quando não utilizados de forma correta, de acordo com as recomendações de aplicação e prazos de carência. Atualmente, a presença de residuos nos alimentos tem sido constante preocupação da população e das autoridades, uma vez que a utilização de produtos químicos continuará a desempenhar significativo papel nos programas de controle nas próximas décadas.

Entre os problemas resultantes da intensa utilização de agrotóxicos destaca-se o destino final das embalagens vazias, que, geralmente, são descartadas em desacordo com os critérios técnicos recomendados. Em face a este problema torna-se imprescindivel o estabelecimento de ação conjunta entre instituições governamentais, empresas produtoras, usuários e demais segmentos da sociedade, principalmente do setor agricola, no sentido da conscientização para uso correto e seguro de agrotóxicos, assim como também para destinação final correta de embalagens vazias e de residuos.

\begin{abstract}
It was acquired, by means of literature revision, information on disposal of pesticide containers and chemical residues. Legal aspects were discussed as well as environmental impact of the intensive use of pesticides, the types of packing materials and the methods (biological, physical and chemical) of disposal, besides the recovering/recycling techniques. It was ended out that there is need of simultaneously action among the
\end{abstract}


governmental institutions, producers and end-user aiming to take advantages understanding the appropriate and safe use of pesticides, remembering the correct final destination of used containers and of pesticides residues.

\section{REFERÊNCIAS BIBLIOGRÁFICAS}

1 AEASP. Associação dos Engenheiros Agrônomos do Estado de São Paulo. Tríplice lavagem de embalagens vazias de agrotóxicos. São Paulo, 1992. 11 p.

2 ANDEF. Associação Nacional de Defesa Vegetal. Triplice lavagem de embalagens vazias de defensivos agricolas. São Paulo, 1992. 8 p. (Folheto Informativo ANDEF).

3 BAA. British Association. Container rising, a practical guide. London, 1991. [100] p.

4 BAPTISTA, L.H.L. de, BAPTISTA, G.C., BRIOSHI, D. Efeito da triplice lavagem na descontaminação de embalagens de pesticidas. I - Dimetoato. In: SIMPÓSIO DE INICIAÇÃO CIENTÍFICA, 2., São Paulo, 1994. Resumos... São Paulo : USP, 1994a.

5 BAPTISTA, L.H.L. de, BAPTISTA, G.C., BRIOSHI, D. Efeito da tríplice lavagem na descontaminação de embalagens de pesticidas. III - Endolsufan e trifluralina. In: SIMPÓSIO DE INICIAÇÃO CIENTÍFICA, 2., São Paulo, 1994. Resumos... São Paulo: USP, 1994 b.

6 BAPTISTA, L.H.L. de, BAPTISTA, G.C., BRIOSHI, D. Efeito da tríplice lavagem na descontaminação de embalagens de pesticidas. I - Cloropirifós e monocrotofós. In: SIMPÓSIO DE INICIAÇÃO CIENTÍFICA, 2., São Paulo, 1994. Resumos... São Paulo: USP, 1994c.

7 BOUWER, H. Agricultural chemicals and groundwater quality. Journal of Soil and Water Conservation, Ankeny, v. 45, p. 184189, 1990.

8 BRASIL. Ministério da Saúde. Decreto $n^{\circ} 98.816$ de 11 de janeiro de 1990. Da destinação final de residuos e embalagens. Diário Oficial [da República Federativa do Brasil], Brasilia, 12 de janeiro de 1990. Seção III, p. 882. 
9 BRIOISHI, D., BAPTISTA, G.C., BAPTISTA, L.H.L. de. Efeito da triplice lavagem na descontaminação de embalagens de pesticidas. II - Monocrotofós e metidation. In: SIMPÓSIO DE INICIAÇÃO CIENTÍFICA, 2., São Paulo, 1994. Resumos... São Paulo : USP, 1994c.

10 BRIOISHI, D., BAPTISTA, G.C., BAPTISTA, L.H.L. de. Efeito da tríplice lavagem na descontaminação de embalagens de pesticidas. II - Fenvelato, endolsufan e lambda-cialotrina. In: CONGRESSO BRASILEIRO DE ENTOMOLOGIA, 15., São Paulo, 1995. Anais... Caxambu : SEB, 1995. p. 480.

11 CIBA-GEIGY. Uma companhia que acredita no Brasil. Stab: Açúcar, álcool e subprodutos, Piracicaba, v. 9, p. 4-7, 1991.

COLVIN, T.S., TURNER, J.H. Applying pesticides. 3.ed. Athens, USA : AAVIM, 1988. 80 p.

COOPERATIVA MISTA BOM JESUS LTDA. Preserve a vida: use adequadamente agrotóxicos. Lapa, 1992. 16 p.

DALDIN, C.A.M. Lavagem de embalagens de agrotóxicos. Ponta Grossa : Associação de Engenheiros Agrônomos dos Campos Gerais, 1993. 30 p.

15 DINNOUTI, L.A. Descarte de embalagens de agrotóxicos. Horticultura Brasileira, Brasília, v. 12, n. 2, p. 203, 1993.

16 DUNN, C.L. Contamination or pollution: the judgement aspect of residue. Residue Reviews, New York, v. 73, p. 93-99, 1980.

17 FAO. Guidelines for the disposal of waste pesticide and pesticide containers on the farm. Roma, 1985. $13 \mathrm{p}$.

FISHER, J. Recycling pesticide containers. Citrus Industry, v. 73, p. 51-53, 1992.

FONTES, L.F. Descarte de embalagens vazias de defensivos agricolas. Summa Phytopatologica, v. 19, p. 65-66, 1993.

20 FOY, C.L., BINGHAM, S.W. Some research approaches toward minimizing herbicidal residue in the environment. Residue Reviews, New York, v. 29, p. 105-135, 1969.

21 GELMINI, G.A. Agrotóxicos: legislação e receituário agronômico. Campinas : CATI, 1991. 103 p. (Manual CATI, n. 29). 
GOELLNER, C., FONTES, L.F. Equipamentos de proteção individual no caso de manipulação dos defensivos agricolas. Boletim técnico, Passo Fundo, v. 1, n. 2, p. 70, 1988. (Séries em Toxicologia).

GOGERTY, R. Farming to keep groundwater clean. International Agricultural Digest, v. 2, p. 12-14, 1990.

HELLAWELL, J. M. Toxic substances in rivers and streams. Environmental Pollution, v. 50, p. 61-85, 1988.

JONES, S.A., JACKSON, G.W. A strategy to present groundwater pollution. Journal of Soil and Water Conservation, Ankeny, v. 45 , p. $236-238,1990$.

JURY, W. A., WINWE, A. M., SPENCER , W.F., FOCHT, D.D.

Transport and transformation of organic chemicals in the soil-airwater ecosystem. Reviews of Environmental Contamination and Toxicology, New York, v. 99, p. 119-164, 1987.

KATAMI, T., NISIKAMA, H., YASHUHARA, A. Emissing of chlorinated compounds by combustion of waste dry-cleanig materials. Chemiosphere, Oxford, v. 24, p. 343-349, 1992.

KEARNY, P.C., WOOLSON, E.A., PLIMMER, J.R., ISENSEE, A.R. Decontamination of pesticides in soil. Residue Reviews, New York, v. 29, p. 137-149, 1969.

KENNEDY, M. V., STOJANOVIC, B. J., SCHUMAN JR., F.L. Chemical and thermal methods for disposal of pesticides. Residue Reviews, New York, v. 29, p. 89-104, 1969.

KISSMANN, K.G. Defensivos agricolas: manual de segurança. São Paulo : BASF, 1987. p. 18-20.

KUNZ, R.P. Destino de embalagens vazias de agrotóxicos. São Paulo: Ciba-Geigy Química, 1992. 43 p.

KUNZ, R.P. Novas tecnologias e diretrizes para embalagens de produtos fitossanitários. Horticlutura Brasileira, Brasilia, v. 11, n. 2, p. 200-202, 1993. 
33 KUNZ, R.P., OZEKI, Y., ATTI, R.J., FAVA, J.F.M. Desenvolvimento e avaliação de um sistema de lavagem de embalagens vazias de agrotóxicos integrado ao pulverizador. In: CONGRESSO BRASILEIRO DE ENGENHARIA AGRICOLA, 22., Ilheus, 1993. Anais... Ilheus : SBEA, 1993. v. 1. p.515-527.

34 LOGAN, T.J. Agricultural pest management practices and groundwater protection. Journal of soil and Walter Conservation, Ankeny, v. 45, p. 201-206, 1990.

35 MAGALLONA, E.D. Pesticide residue and relevant directions for developing countries. Residue Reviews, New York, v. 73, p. 1325, 1980.

36 MARER, P.J., FLINT, M.L., STIMMANN, M.W. The safe and effective use of pesticides. Davis : University of California, 1988. 387 p.

37 MUNNECKE, D.M. Chemical, physical and biological methods for the disposal and detoxification of pesticides. Residue Reviews, New York, v. 70, p. 1-26, 1979.

38 MUSUMECI, M.R. Defensivos agricolas e sua interação com a microbiota do solo. In: CARDOSO, E.J.N., TSAI, S.M., NEVES, M.C. Microbiologia do solo. Campinas : Sociedade Brasileira de Ciência do Solo, 1992. p. 341-360.

NACA. National Agricultural Chemicals. Empty container disposal: safe practices for agricultural users. Washington D.C., 1992. 8 p.

40 OLIVEIRA, S. de S. Programa Nacional de recolhimento e destinação adequada de embalagens de agrotóxicos. Horticultura Brasileira, Brasilia, v. 11, n. 2, p. 203, 1993.

41 SANDMANN, E.R.I.C., LOOS, M. A., WANDYK, L.P. The microbial degradation of 2,4-dichlorophenoxyacetic acid in soil. Reviews of Environmental Contamination and Toxicology, New York, v. 101, p. 1-53, 1988.

42 SEMA. Secretaria do Meio Ambiente. SUREHMA. Agrotóxicos: a realidade do Paraná. Curitiba : MAR, 1992. 94 p.

43 SETHUNATHAN, N. Microbial degradation of inseticides in flood soil in anaerobic culture. Residue Reviews, New York, v. 47, p. 143165, 1973. 
SMITH, R.K. Gerenciamento de descarte de embalagens de agroquimicos: uma visão geral e sugestões para o desenvolvimento de estratégias para o futuro. In: SEMINÁRIO INTERNACIONAL SOBRE DISPOSIÇÃO FINAL DE EMBALAGENS DE AGROTÓXICOS, 1., Toledo, 1994. Anais... Toledo, 1994. $16 \mathrm{p}$.

SOBRAL, G.M.O., BARROTTI, A. Tratamento e disposição final dos residuos contendo pesticidas organofosforados. In: CONGRESSO BRASILEIRO DE LIMPEZA PÚBLICA, 3., São Paulo, 1978. Anais... São Paulo : Companhia de Tecnologia de Saneamento Ambiental, 1978. p. 31-35.

SOUSA, A.C., ALMEIDA, W.F., LINDENBERG, R.B., CAMARGO, P.A.M. Defensivos agrícolas: contribuição ao uso adequado e prevenção nas intoxicações. Curitiba : Secretaria de Estado da Agricultura, Depto. de Fiscalização, 1979. 108 p.

TRUMAN, L.C., BENNETT, G.W., BUTTS, W.L. Scientific guide to pest control operations for pesticide applicator training. Duluth: Jovanovich, 1982. 276 p.

WEAVER, M.J. Methods for safe handling, storage, and disposal of pesticides used in research and demonstration. In: HICKEY, K.D. Methods for evaluating pesticides for control of plant pathogens. St. Paul : APS, 1986. p. 3-10 